\title{
Über die Purinbasen der menschlichen Placenta.
}

\author{
Von
}

T. Kikkoji und Risaburo Iguchi.

(Aus dem medizinisch-chemischen Institut der Universität zu Kyoto.)

(Der Redaktion zugegangen am 10. Juni 1907.)

Über die chemische Zušsammensetzung der menschlichen Placenta ist man verhältnismäßig wenig unterrichtet und die spärlichen Angaben in Betreff der darin enthaltenen Purinbasen rühren meistens von Forschern her, die sich mit der Frage nach der Art der autolytischen Produkte der Placenta beschäftigt hatten.

Ascoli $\left.{ }^{1}\right)$ unterwarf die Placenten der Autolyse und fand dabei, daß als Endprodukte Tyrosin, Leucin und Nucleinbasen entstanden. Die Trennung der einzelnen Nucleinbasen aber hat er nicht vorgenommen.

Basso ${ }^{2}$ ) konnte in einer Arbeit über die Autolyse der Placenta zeigen, daß bei der Digestion der zerhackten Placenten mit Chloroformwasser bei $40^{\circ}$ das latente Hypoxanthin in das manifeste übergeführt wurde. Es fehlt hier auch ausführliche Mitteilung, wie er Hypoxanthin erkannt hat.

Angesichts dieser Unsicherheit haben wir für nützlich gehalten, die Art der Purinbasen, die in der normalen Placenta enthalten sind, festzustellen.

Bei der Beschaffung des Materials hat Herr Prof. Takayama, Vorstand der hiesigen Frauenklinik, uns freundliches Entgegenkommen gezeigt; dafür sagen wir ihm unseren besten Dank.

9 frisch ausgestoßene Placenten wurden von den Eihäuten und vom Nabelstrange befreit, mit einer 0,9\% igen Kochsalz-

1) Ascoli, Zentralbl. f. Physiol., 1902, Nr. 51, S. 124.

2) Bass o, Archiv f. Gynäkol., Bd. LXXVI, S. 162.

Hoppe-Seyler's Zeitschrift f. physiol. Chemie. LII. 
lösung ausgewaschen, auf einer Fleischmühle gemahlen und nach der bekannten Methode ${ }^{1}$ ) auf die Purinbasen verarbeitet. Zur Isolierung der einzelnen Purinbasen zerlegten wir die Silberfällung mit verdünnter Salzsäure und filtrierten heiß. Das eingeengte Filtrat gab beim Zusatz von überschüssigem Ammoniak einen reichlichen Niederschlag. Dieser Niederschlag wurde durch Auflösung in verdünnter Natronlauge und Umfällung mit Essigsäure gereinigt und der Analyse unterworfen.

0,2834 g Substanz gaben $0,4141 \mathrm{~g} \mathrm{CO}_{2}=39,84^{\circ} \% \mathrm{C}$ und $0,0879 \gg \mathrm{H}_{2} \mathrm{O}=3,47 \% \mathrm{H}$

$0,1334 \mathrm{~g}$ Substanz gaben $52 \mathrm{ccm}$ feuchten Stickstoffs bei $12^{\circ} \mathrm{C}$. und $764 \mathrm{~mm} \mathrm{~B}$., entsprechend $46,5 \% \mathrm{~N}$.

Berechnet für $\mathrm{C}_{5} \mathrm{H}_{5} \mathrm{~N}_{5} \mathrm{O}$ :

$$
\begin{array}{lc}
\mathrm{C}=39,73 \% & \text { Gefunden: } \\
\mathrm{C}=3,31 \% & 39,84 \% \\
\mathrm{H}=4,47 \% & 3,47 \% \\
\mathrm{~N}=46,40 \% & 46,50 \%
\end{array}
$$

Die ammoniakalischen Filtrate vom Guanin wurden nach Fntfernung des Ammoniaks mit Salzsäure schwach angesäuert und mit einer gesättigten Lösung von Natriumpikrat versetzt; es schied sich sofort ein Pikrat in gelben Nadeln aus. Das durch Umkrystallisation aus heißem Wasser gereinigte Pikrat schmolz unter Zersetzung bei $280^{\circ} \mathrm{C}$. und gab folgende Analysenwerte.

$0,1677 \mathrm{~g}$ Substanz gaben $43,5 \mathrm{ccm}$ feuchten Stickstoffs bei $12{ }^{\circ}$ C. und $758 \mathrm{~mm}$ B., entsprechend $30,71 \% \mathrm{~N}$.

Berechnet für $\mathrm{C}_{5} \mathrm{H}_{5} \mathrm{~N}_{5} \cdot \mathrm{C}_{6} \mathrm{H}_{8} \mathrm{~N}_{8} \mathrm{O}_{7}$ :

$$
\mathrm{N}=30,82 \%
$$

Gefunden:

$30,71 \%$

Die vom Adeninpikrat abfiltrierte Flüssigkeit wurde mit Salpetersäure und Benzol von Pikrinsäure befreit und mit ammoniakalischer Silberlösung gefällt. Die Silberfällung wurde mit Salzsäure auf dem Wasserbade digeriert und filtriert, das Filtrat wurde zur Trockene eingedampft und der Rückstand, nachdem er durch mehrmaliges Eindunsten mit Alkohol von überschüssiger Salzsäure befreit wurde, mit wenig Wasser übergossen, längere Zeit bei $40^{\circ}$ digeriert und 24 Stunden stehen

1) Hop pe-Seylers Handbuch d. physiolog.u. pathol.-chem. Analyse, 7. Aufl., 1903, S. 573. 
gelassen. Die dabei ausgeschiedene Masse gab schöne Xanthinprobe und Weidelsche Reaktion.

$0,1622 \mathrm{~g}$ Substanz gaben 50,5 ccm feuchten Stickstoffs bei $15^{\circ} \mathrm{C}$. und $765,4 \mathrm{~mm} \mathrm{~B}$., entsprechend $36,74 \% \mathrm{~N}$.

Berechnet für $\mathrm{C}_{5} \mathrm{H}_{4} \mathrm{~N}_{4} \mathrm{O}_{2}$ : Gefunden:

$$
\mathrm{N}=36,90^{\circ} \% \quad 36,74{ }^{\circ} \%
$$

Aus dem Filtrat vom Xanthin schieden sich nach dem Zusatz von einer konzentrierten, wässerigen Pikrinsäurelösung und längerem Stehen schwere tafelförmige Krystalle aus, die durch Behandeln mit Silbernitrat in das Silberpikrat übergeführt wurden.

0,2932 g Substanz gaben $0,0661 \mathrm{~g} \mathrm{Ag}=22,54 \% \mathrm{Ag}$

Berechnet für $\mathrm{C}_{5} \mathrm{H}_{3} \mathrm{AgN}_{4} \mathrm{O} \cdot \mathrm{C}_{6} \mathrm{H}_{8} \mathrm{~N}_{8} \mathrm{O}_{7}$ :

$$
\mathrm{Ag}=22,90 \%
$$

Gefunden:

$22,54 \%$

Wie aus den geschilderten Versuchsergebnissen ersichtlich ist, haben wir mit Sicherheit in der menschlichen Placenta nachgewiesen: Guanin, Adenin, Xanthin und Hypoxanthin.

Die Untersuchung über die Zusammensetzung und die Spaltungsprodukte der Nucleinsäure aus der Placenta hat der eine von uns (Kikk oji) bereits begonnen und hofft bald einiges darüber mitteilen zu können. 